\title{
Erratum 2
}

\section{Validation of the 2009 TNM Classification for Renal Cell Carcinoma: Comparison with the 2002 TNM Classification by Concordance Index}

\author{
Chunwoo Lee, Dalsan You, Junsoo Park, In Gab Jeong, Cheryn Song, Jun Hyuk Hong, \\ Hanjong Ahn, Choung-Soo Kim
}

[Korean J Urol 2011 August;52(8):524-530. Published online 2011 August 24.http: / / dx.doi.org / 10.4111/kju.2011.52.8.524]

Table 2 is error. The Table 2 should be corrected as follows.

TABLE 2. Univariate and multivariate cox regression analyses of the abilities of the 2002 primary tumor classifications to predict cancer-specific survival

\begin{tabular}{|c|c|c|c|c|}
\hline Classification & $\begin{array}{c}\text { Univariate analyses } \\
\text { HR }(95 \% \mathrm{CI})\end{array}$ & $\mathrm{p}$-value & $\begin{array}{c}\text { Multivariate analyses } \\
\text { HR }(95 \% \mathrm{CI})\end{array}$ & p-value \\
\hline \multicolumn{4}{|l|}{2002 primary tumor classification } & \\
\hline $\mathrm{T} 1 \mathrm{~b}$ & $4.10(2.30-7.31)$ & $<0.001$ & $3.37(1.89-6.01)$ & $<0.001$ \\
\hline $\mathrm{T} 2$ & $8.02(4.51-14.27)$ & $<0.001$ & $4.77(2.65-8.57)$ & $<0.001$ \\
\hline T3a & $19.24(11.02-33.59)$ & $<0.001$ & $9.32(5.24-16.61)$ & $<0.001$ \\
\hline T3b & $27.86(16.04-48.38)$ & $<0.001$ & $9.73(5.43-17.45)$ & $<0.001$ \\
\hline T3c & $57.21(22.32-146.63)$ & $<0.001$ & $17.64(6.58-47.34)$ & $<0.001$ \\
\hline $\mathrm{T} 4$ & $50.11(24.43-102.77)$ & $<0.001$ & $11.23(5.16-24.48)$ & $<0.001$ \\
\hline $\begin{array}{l}2002 \text { lymph node classification } \\
\mathrm{Nx}+\mathrm{N} 0\end{array}$ & NA & & & \\
\hline N1 & & & $2.46(1.42-4.28)$ & 0.001 \\
\hline N2 & & & $1.46(0.95-2.23)$ & 0.083 \\
\hline $\begin{array}{l}2002 \text { metastasis classification } \\
\text { M0 }\end{array}$ & NA & & & \\
\hline M1 & & & $12.79(9.38-17.43)$ & $<0.001$ \\
\hline c index & $0.810(0.782-0.839)$ & & $0.906(0.886-0.925)$ & \\
\hline
\end{tabular}

HR: hazard ratio, CI: confidence interval, NA: not applicable 